Editorial

\title{
Neurosurgeon Under the Shadow of COVID-19!
}

\author{
Abrar Ahad Wani ${ }^{1}$ Mohsin Fayaz ${ }^{1}$ \\ ${ }^{1}$ Department of Neurosurgery, SKIMS, Srinagar, Jammu and \\ Kashmir, India \\ Indian J Neurosurg:2020;9:1-2
}

The wave of Coronavirus Disease 2019 (COVID-19) pandemic has engulfed the entire world and our situation is not an exception. At the forefront are the health care workers (HCWs) who are at a high risk of transmission of COVID-19 while discharging their duties. The situation being unprecedented, the response to it by HCWs is also varied. Many HCWs, without any fear and subsumed in their love for humanity, have lost their lives with a missionary zeal, as Shakespeare wrote in his famous play, "Cowards die many times before their deaths; the valiant never taste of death but once" (Julius Caesar). This sacrifice of theirs is commendable, but the safety concern of HCWs is a major priority of the health delivery system. We cannot afford to lose our health warriors, as the health care system will crumble in the present scenario if the pandemic continues unabated. This unprecedented challenge demands treatment guidelines in the neurosurgery domain. The recommendations need to be framed by taking into the medical, ethical, and logistic scenario into consideration. The guidelines need to be related to patients, medical facilities, HCW, and focused on the specialty. In every specialty there are some peculiarities, hence guidelines cannot be generalized for all the specialties. Just to quote an example, the risks of operating on the appendix are entirely different from operating a pituitary tumor by endonasal approach. ${ }^{1}$

For every patient requiring surgery, the need of the procedure should be established to determine the medical risks incurred by delaying the intervention in a patient. The spectrum is wide ranging, from delayed surgery (like meningioma, spinal dysraphism) to immediate intervention (aneurismal subarachnoid hemorrhage). In a hospital where emergency reception is flooded with COVID patients and simultaneously the non-COVID areas are also receiving patients, there is a competition for the resources. Lot of ethical issues come up like who will be shifted to ventilator when the number of patients requiring artificial ventilation is far more than ventilators available. In case an elderly patient is not provided

Address for correspondence Abrar Ahad Wani, MCh, Department of Neurosurgery, Sher-i-Kashmir Institut of Medical Sciences, Soura, Srinagar, Jammu and Kashmir 190011, India (e-mail: drabrarahadwani@gmail.com). the ventilator, which is given to the young patient, the ethical dilemma is in case the former has less severe illness and would recover if provided support unlike the young man who despite support dies! This and many other issues come up in absence of guidelines for the treatment. The COVID-19 outbreak will be unpredictable for the next few months as there is still a speculative assumption about the precarious nature and transmission of virus. The risk-benefit ratio has to be considered not only for the patient but also for the community as a whole. ${ }^{2}$ The risk to the patient should include the cumulative risk of doing the procedure and the possibility of contracting the virus during the hospital stay, thus, exposing the patient and entire health care staff. This can jeopardize the functioning of the already overwhelmed health care facility. ${ }^{3,4}$

Logistic feasibility is a major concern, which requires extensive thought by the administrative personnel of the hospital. The availability of beds, staff, intensive care unit, personal protection equipment (PPE), etc. should be sought out before hand with ancillary departments. This is an important facet as this varies with the region. In developed countries like the United States, there is shortage of both work force and equipment so the scenario in undeveloped countries can be just imagined. The HCWs can be seen protesting all over the world for shortage of simple equipment like PPE and masks when the military expenditure of all the countries is jumping in an exponential manner. United States alone has a defense budget of nearly 730 billion US dollars and they are facing shortage of medical equipment. Humankind is spending more in destroying itself than in saving itself!

The current situation is of stress and it demands wider collaboration between various departments in the hospital and administration so that the effective guidelines are framed with an option to be revised as the data availability increases. There is a famous quote "It's not the stress that kills $u s$, it is our reaction to it"(Hans Selye). HCWs need to practise
DOI https://doi.org/

$10.1055 / \mathrm{s}-0040-1712786$

ISSN 2277-954X.
(C2020 Neurological Surgeons' Society License terms of India 
stress-relieving therapies as much as possible.The current situation will not last indefinitely as human race has faced times that are far more difficult. We need to be optimistic and remember,"It is during our darkest moments that we must focus to see the light"(Aristotle).

\section{Conflict of Interest}

None declared.

\section{References}

1 Workman AD, Welling DB, Carter BS, et al. Endonasal Instrumentation and Aerosolization Risk in the Era of COVID-19: Simulation, Literature Review, and Proposed Mitigation Strategies. Available at: https://onlinelibrary.wiley.com/doi/pdf/10.1002/ alr.22577. Accessed May 5, 2020
2 Grasselli G, Pesenti A, Cecconi M. Critical Care Utilization for the COVID-19 Outbreak in Lombardy, Italy: Early Experience and Forecast During an Emergency Response. JAMA 2020. Doi: $10.1001 /$ jama.2020.4031 [epub ahead of print]

3 Spina S, Marrazzo F, Migliari M, Stucchi R, Sforza A, Fumagalli R. The response of Milan's Emergency Medical System to the COVID-19 outbreak in Italy. Lancet 2020;395(10227) :e49-e50

4 Johns Hopkins University \& Medicine. Coronavirus Resource Center. Track Reported Cases of COVID-19. Available at: https:// coronavirus.jhu.edu/map.html. Accessed May 5, 2020 